\title{
BMJ Open Catastrophic health expenditure according to employment status in South Korea: a population-based panel study
}

\author{
Jae Woo Choi, ${ }^{1,2}$ Tae Hyun Kim, ${ }^{2,3}$ Sung In Jang, ${ }^{2,4}$ Suk Yong Jang, ${ }^{2,4}$ \\ Woo-Rim Kim, ${ }^{1,2}$ Eun Cheol Park ${ }^{2,4}$
}

To cite: Choi JW, Kim TH, Jang SI, et al. Catastrophic health expenditure according to employment status in South Korea: a populationbased panel study. BMJ Open 2016:6:e011747.

doi:10.1136/bmjopen-2016011747

- Prepublication history for this paper is available online. To view these files please visit the journal online (http://dx.doi.org/10.1136/ bmjopen-2016-011747).

Received 2 March 2016 Accepted 23 June 2016

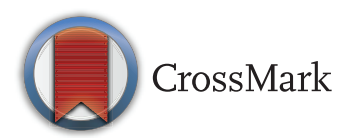

${ }^{1}$ Department of Public Health, Graduate School, Yonsei University, Seoul, Korea ${ }^{2}$ Institute of Health Services Research, Yonsei University College of Medicine, Seoul, Korea

${ }^{3}$ Department of Hospital Administration, Graduate School of Public Health, Yonsei University, Seoul, Korea

${ }^{4}$ Department of Preventive Medicine, Yonsei University College of Medicine, Seoul, Korea

Correspondence to Dr Eun Cheol Park; ECPARK@yuhs.ac

\section{ABSTRACT}

Objectives: Catastrophic health expenditure (CHE) means that the medical spending of a household exceeds a certain level of capacity to pay. Previous studies of CHE have focused on benefits supported by the public sector or high medical cost incurred by treating diseases in South Korea. This study examines variance of $\mathrm{CHE}$ in these households according to changes in employment status. We also determine whether a relationship exists according to income level.

Design: A longitudinal study.

Setting: We used the Korean Welfare Panel Study (KOWEPS) conducted by the Korea Institute.

Participants: The data came from 5335 households during 2009-2012.

Outcome measure: $\mathrm{CHE}$, defined as health expenditures that were $40 \%$ greater than the ability of the household to pay.

Results: Households with people who experienced changes in job status from employed to unemployed (OR 2.79, $95 \% \mathrm{Cl} 2.06$ to 3.78 ) or were unemployed with no status change (OR $1.57,95 \% \mathrm{Cl} 1.28$ to 1.92$)$ were more likely to incur CHE than those containing people who were consistently employed. In addition, low-income families with members who had either lost a job (OR 3.52, $95 \% \mathrm{Cl} 2.44$ to 5.10 ) or were already unemployed (OR 1.67, 95\% Cl 1.29 to 2.16) were more likely to incur CHE than those with family members with a consistent job.

Conclusions: Given the insecure employment status of people with low income, they are more likely to face barriers in obtaining needed health services. Meeting their healthcare needs is an important consideration.

\section{INTRODUCTION}

Catastrophic health expenditure (CHE) means that medical spending of a household exceeds a certain level of capacity to pay. Various elements affect the financial burden of medical expenditure, one of which is the nature of the healthcare system. In 2012, the ratio of total medical expenses financed by

\section{Strengths and limitations of this study}

- This study is meaningful because it is the first to examine the impact of employment status changes on catastrophic health expenditure (CHE) in low-income people as well as the general population of South Korea.

- The longitudinal design of this research allows us to assess the continuity and stability of a few attributes of a sample group by repeatedly examining the same people.

- Comprehensive medical expenses, including expenses for health functional food and check ups etc, were used, even though the WHO defined CHE as inevitable and involuntary spending; therefore, CHE may be overestimated.

- Because diverse criteria (10-40\%) have been used as the threshold of CHE, comparing our results with those of previous research is difficult.

- Since a few conditions may not have been diagnosed, the actual prevalence of chronic diseases is probably higher than that reported in the Korean Welfare Panel Study (KOWEPS).

the public sector was only $55 \%$ in South Korea, which is lower than the Organization for Economic Cooperation and Development (OECD) average $(72 \%)$, and the fourth lowest OECD level of expenditure after the USA (48\%), Chile (49\%) and Mexico $(51 \%) .{ }^{1}$ The moderate impact of insurance cover on financial protection shows that people with health insurance are still paying fairly high out-of-pocket (OOP) payments. ${ }^{2}$ Since the system that provides low benefit accounts for high OOP payment, households requiring a lot of medical utilisation have a much greater financial burden from medical spending. Another requisite affecting CHE is excessive OOP payment. In South Korea, medical expenses of households consist of $35.2 \%$ (2011) in total expenditure, a far 
higher level than the OECD average of $19.6 \%$ (2011), which may pose serious issues for low-income families. ${ }^{3}$ Households with high spending on medical costs due to diseases or accident have to reduce their consumption and may have substantial financial problems. ${ }^{4} 5$ The final element is the ability of the household to pay. CHE is a relative concept that has to consider ability to pay as well as level of medical cost because the same level of medical spending gives greater burden to low-income households than to the rich. ${ }^{6}$ Previous studies of CHE have focused on benefits supported by the public sector or high medical costs incurred by treating diseases in South Korea. ${ }^{7-11}$ However, few studies on ability to pay, which constitutes the denominator of $\mathrm{CHE}$, have been reported.

The ability to pay generally explains disposable income of households, and income mainly consists of earned income, business income and property income. Reduction in income may be affected by changes in economic status. A previous study showed that households in which people with a disability had recently lost a job (OR 2.30, 95\% CI 1.34 to 3.94) or had been unemployed (OR $1.68,95 \%$ CI 1.15 to 2.44 ) were more likely to incur CHE than households of people with consistent jobs. ${ }^{12}$ However, there is no clear evidence for a relationship between changes in employment status and CHE in the general population.

Therefore, this study examined how the burden of medical expenses in these households varies according to changes in economic status. This research also examined the association by dividing the population by income level: low-income, middle-income and highincome. Low-income populations normally have greater financial burden of medical expenses because their ability to pay is relatively low and the amount of medical utilisation due to bad health is regressive for income. ${ }^{13-15}$ In addition, medical costs are regressive for income in a limited health benefit system for low-income groups. ${ }^{16-18}$

\section{METHODS}

Data

This study used the 2009-2012 Korean Welfare Panel Study (KOWEPS), representative of national households, conducted by the Korean Institute for Health and Social Affairs along with the Seoul National University Social Welfare Research Center. KOWEPS data were collected using an interview research method where the interviewer questioned and recorded the answers of the interviewees. A stratified cluster systematic method was used to select the sample of households for the research. This survey was conducted with the goal of understanding the living conditions and welfare demands of the population group, and to evaluate the effectiveness of policies in utilising information on policies. These data are appropriate for analysis of the characteristics of people with low income, such as Medical Aid beneficiaries, because more than half of the sample consists of low- income households (below 60\% of median income), and the data come from various questionnaires that can be used for in-depth examination of utilisation of healthcare. In addition, the results of the analysis can be easily generalised because KOWEPS has conducted a survey of all people including those in rural areas. The panel consists of 18856 individuals from a national probability sample of 7072 households in South Korea who have been surveyed annually since 2006. The sample was selected using systematic two-stage stratified cluster sampling on 2005 census data. KOWEPS also used poststratification weights based on 2005 census data, and data were weighted by (1) a primary sampling unit and (2) intentionally oversampling low-income households. Further details of the sample design, methods and datasets can be found elsewhere (http:www.koweps.re.kr/). This study received ethics approval from the institutional review board of Yonsei University Graduate School of Public Health.

\section{Study sample}

A stratified cluster systematic method was used to select the sample of households used for this study. The selected records included data from the 4th wave (2009), 5th wave (2010), 6th wave (2011) and 7th wave (2012) during the 4-year research period. Households that were dropped or added during this period were excluded and, subsequently, records from 5335 households were queried.

\section{Dependent variable}

The dependent variable was $\mathrm{CHE}$ as defined by the WHO. According to the WHO, CHE occurs when OOP spending exceeds $40 \%$ of a household's capacity to pay, and this standard should be altered appropriately for each country. ${ }^{19}{ }^{20}$ A household's capacity to pay was defined as the amount of money spent per month, excluding food expenses. ${ }^{21}$ OOP expenditure is a payment made by a household when receiving a health service. Medical and drug costs resulting from emergency and outpatient care, as well as from hospitalisations, were included as OOP payments, whereas transportation and nursing costs were excluded. Thus, CHE was defined as health expenditures that were $40 \%$ greater than the ability of the household to pay.

\section{Independent variable}

The main independent variable for this study was change in employment status of an individual. Each change in employment for each year was measured between consecutive years. Households were stratified according to four categories with respect to job status: employed-no change; employed-then-unemployed; unemployed-then-employed; unemployed-no change.

\section{Covariates}

Several covariates were used to analyse demographic and socioeconomic characteristics and health status. 
Demographic characteristics included sex, age, marital status and socioeconomic factors such as education and income level. Income level was measured by summing the total family income, including the income from employment, assets, pensions, financial support from the government, and other sources. Household income was adjusted by taking the square root of the number of household members. As a proxy for health status, selfrated health, depression and chronic diseases were used to control for the participant's health condition and health behaviour, which can affect healthcare utilisation. In addition, this study examined the following household characteristics: type of health insurance; number of people over 65 years; total number of family members; number of people with a disability.

\section{Statistical analysis}

The frequency with which CHE was incurred overall after demographic, socioeconomic and health status had been accounted for was determined by the $\chi^{2}$ test. To identify factors associated with CHE and, in particular, to examine the relationship between changes in economic status and CHE, this study used the GLIMMIX procedure under the marginal model (populationaverage model). OR was calculated through the regression coefficient gained using the generalised linear mixed model (GLMM) and is presented with $95 \%$ CI. SAS V.9.3 was used for data analysis.

\section{RESULTS}

General characteristics of households analysed in this study are shown in table 1 . Of the 5335 households, 220 (4.1\%) experienced CHE. At the individual level, people over 65 years had a higher proportion of CHE than younger individuals or those with a lower educational level. People with negative self-rated health or those having chronic diseases or depression also experienced a higher frequency of CHE. A significant difference in the proportion of employment status changes and CHE was also observed. At the household level, lowincome households had a higher proportion of CHE than higher-income households. Households containing people over 65 years or people with a disability were associated with a higher frequency of CHE. A significant difference was observed between the number of family members in a household and the frequency of CHE. However, no significant relationship was observed between CHE and sex or type of health insurance.

The results for factors associated with CHE in South Korean households are shown in table 2. Female householders were more likely to experience CHE than male householders (OR 1.42, 95\% CI 1.05 to 1.93). People living with a spouse had a higher risk of CHE than those who were divorced or separated. People with negative self-rated health were more likely to experience CHE, and those having chronic diseases or depression were more likely to experience $\mathrm{CHE}$ than those no having such diseases. Households with family members who had experienced changes in job status from employed to unemployed or who were unemployed with no change were more likely to incur CHE than those with family members with a consistent job. Households that benefited from the Medical Aid programme were less likely to experience CHE than those with national health insurance. Households that included an older person or a person with a disability were more likely to experience CHE than households that did not. Households with two family members were also more likely to incur CHE than households with only one person.

Results for changes of economic status associated with CHE in households according to income level are shown in table 3. After adjustment for all variables used in table 1, there was no significant difference in CHE associated with changes in middle-income (except unemployed with no change) and high-income households. However, low-income households that experienced changes in job status, either from employed to unemployed (OR 3.52, 95\% CI 2.44 to 5.10 ) or were unemployed with no change (OR $1.67,95 \%$ CI 1.29 to 2.16), were more likely to incur CHE than those with a consistent job.

\section{DISCUSSION}

Our results indicate that changes from employed to unemployed or those who were unemployed with no change were associated with CHE among the general population in South Korea. In particular, unemployed households were 2.8 times more likely to experience CHE, and this may be because of interruption of household income. A recent study showed that unemployed households were 2.3 times more likely to experience unmet need for economic reasons. ${ }^{22}$ These households will have a burden of spending on medical costs because of disruption of economic activities. The financial burden of medical expenses results in poor health if treatment for diseases is not received at appropriate times and the illness can represent loss of working ability. In other words, such conditions may lead to a vicious cycle of poverty. ${ }^{23} 24$

In addition, in the subpopulation analyses, the association between change in employment status and CHE was affected by income level. This study found that, in low-income households, job status, either changes from employed to unemployed or unemployed with no change, is associated with CHE compared with continuous employment. A previous study on low-income levels showed a rate of occurrence of CHE of $7.8 \%$ in the poor, whereas only $2.2 \%$ of the general population (including the rich) experienced CHE. ${ }^{8}$ The reason that low-income people are more affected by changes in employment status may be their relatively low purchasing power. ${ }^{25}$ Most of their ability to pay is accounted for by earned income, whereas the general population has higher business and/or property income in addition to 
Table 1 General characteristics of households analysed

\begin{tabular}{|c|c|c|c|c|c|c|}
\hline \multirow[b]{2}{*}{ Variable } & \multicolumn{5}{|c|}{ Catastrophic health expenditure (CHE) } & \multirow[b]{2}{*}{ p Value } \\
\hline & Total & With CHE & Per cent & Without CHE & Per cent & \\
\hline $\begin{array}{l}\text { Total } \\
\text { Householder level }\end{array}$ & 5335 & 220 & 4.1 & 5115 & 95.9 & \\
\hline Sex & & & & & & 0.5801 \\
\hline Male & 3841 & 162 & 73.6 & 3679 & 71.9 & \\
\hline Female & 1494 & 58 & 26.4 & 1436 & 28.1 & \\
\hline Age (years) & & & & & & $<0.0001$ \\
\hline$\leq 39$ & 719 & 8 & 3.6 & 711 & 13.9 & \\
\hline $40-59$ & 1977 & 28 & 12.7 & 1949 & 38.1 & \\
\hline$\geq 60$ & 2638 & 184 & 83.6 & 2454 & 48.0 & \\
\hline Education & & & & & & $<0.0001$ \\
\hline Below elementary school & 1859 & 120 & 54.5 & 1739 & 34.0 & \\
\hline Middle or high school & 2226 & 68 & 30.9 & 2158 & 42.2 & \\
\hline Above college & 1250 & 32 & 14.5 & 1218 & 23.8 & \\
\hline Marital status & & & & & & 0.0082 \\
\hline Married & 3436 & 161 & 73.2 & 3275 & 64.0 & \\
\hline Single & 281 & 5 & 2.3 & 276 & 5.4 & \\
\hline Divorced or separated & 1617 & 53 & 24.1 & 1564 & 30.6 & \\
\hline Self-rated health & & & & & & $<0.0001$ \\
\hline Good & 2739 & 53 & 24.1 & 2686 & 52.5 & \\
\hline Normal & 1204 & 49 & 22.3 & 1155 & 22.6 & \\
\hline Bad & 1392 & 118 & 53.6 & 1274 & 24.9 & \\
\hline Chronic disease & & & & & & $<0.0001$ \\
\hline Yes & 3074 & 182 & 82.7 & 2892 & 56.5 & \\
\hline No & 2261 & 38 & 17.3 & 2223 & 43.5 & \\
\hline Depression & & & & & & $<0.0001$ \\
\hline Yes & 1670 & 95 & 43.2 & 1575 & 30.8 & \\
\hline No & 3508 & 113 & 51.4 & 3395 & 66.4 & \\
\hline Economic status & & & & & & $<0.0001$ \\
\hline Employed $\rightarrow$ employed & 3246 & 85 & 38.6 & 3161 & 61.8 & \\
\hline Unemployed $\rightarrow$ employed & 233 & 5 & 2.3 & 228 & 4.5 & \\
\hline Employed $\rightarrow$ unemployed & 274 & 19 & 8.6 & 255 & 5.0 & \\
\hline Unemployed $\rightarrow$ unemployed & 1582 & 111 & 50.5 & 1471 & 28.8 & \\
\hline Household level & & & & & & \\
\hline Income & & & & & & $<0.0001$ \\
\hline High & 1225 & 15 & 6.8 & 1210 & 23.7 & \\
\hline Middle & 1525 & 67 & 30.5 & 1458 & 28.5 & \\
\hline Low & 2585 & 138 & 62.7 & 2447 & 47.8 & \\
\hline Type of health insurance & & & & & & 0.9188 \\
\hline National health insurance & 4716 & 194 & 88.2 & 4522 & 88.4 & \\
\hline Medical-aid & 619 & 26 & 11.8 & 593 & 11.6 & \\
\hline Number of people with a disability & & & & & & $<0.0001$ \\
\hline 0 & 4213 & 145 & 65.9 & 4068 & 79.5 & \\
\hline$\geq 1$ & 1122 & 75 & 34.1 & 1047 & 20.5 & \\
\hline Number of people over 65 years & & & & & & $<0.0001$ \\
\hline 0 & 2710 & 40 & 18.2 & 2670 & 52.2 & \\
\hline 1 & 1672 & 68 & 30.9 & 1604 & 31.4 & \\
\hline$\geq 2$ & 953 & 112 & 50.9 & 841 & 16.4 & \\
\hline Number of household members & & & & & & $<0.0001$ \\
\hline 1 & 1283 & 40 & 18.2 & 1243 & 24.3 & \\
\hline 2 & 1612 & 121 & 55.0 & 1491 & 29.1 & \\
\hline$\geq 3$ & 2440 & 59 & 26.8 & 2381 & 46.5 & \\
\hline
\end{tabular}

earned income than the poor. This indicates that, when there is a need for medical services in a low-income household, low purchasing power does not stop that household from paying for healthcare. This causes high healthcare expenses relative to purchasing ability, which can lead to low-income families experiencing CHE. ${ }^{26}$

Regarding householder level, households headed by women or having negative self-related health, chronic 
Table 2 Factors associated with catastrophic health expenditure (CHE)

\begin{tabular}{|c|c|c|}
\hline \multirow[b]{2}{*}{ Variable } & \multicolumn{2}{|l|}{ CHE } \\
\hline & Adjusted OR & $95 \% \mathrm{Cl}$ \\
\hline \multicolumn{3}{|l|}{ Householder level } \\
\hline \multicolumn{3}{|l|}{ Sex } \\
\hline Male & 1.00 & \\
\hline Female & 1.42 & 1.05 to 1.93 \\
\hline \multicolumn{3}{|l|}{ Age (years) } \\
\hline$\leq 39$ & 1.00 & \\
\hline $40-59$ & 1.33 & 0.74 to 2.38 \\
\hline$\geq 60$ & 1.54 & 0.80 to 2.97 \\
\hline \multicolumn{3}{|l|}{ Education } \\
\hline Above college & 1.00 & \\
\hline Middle or high school & 1.00 & 0.75 to 1.34 \\
\hline Below elementary school & 1.29 & 0.96 to 1.75 \\
\hline \multicolumn{3}{|l|}{ Marital status } \\
\hline Married & 1.00 & \\
\hline Single & 1.00 & 0.53 to 1.91 \\
\hline Divorced or separated & 0.58 & 0.40 to 0.84 \\
\hline \multicolumn{3}{|l|}{ Self-rated health } \\
\hline Good & 1.00 & \\
\hline Normal & 1.23 & 0.96 to 1.59 \\
\hline Bad & 1.97 & 1.54 to 2.51 \\
\hline \multicolumn{3}{|l|}{ Chronic disease } \\
\hline No & 1.00 & \\
\hline Yes & 1.72 & 1.31 to 2.27 \\
\hline \multicolumn{3}{|l|}{ Depression } \\
\hline No & 1.00 & \\
\hline Yes & 1.47 & 1.23 to 1.76 \\
\hline \multicolumn{3}{|l|}{ Economic status } \\
\hline Employed $\rightarrow$ employed & 1.00 & \\
\hline Unemployed $\rightarrow$ employed & 0.95 & 0.59 to 1.53 \\
\hline Employed $\rightarrow$ unemployed & 2.79 & 2.06 to 3.78 \\
\hline Unemployed $\rightarrow$ unemployed & 1.57 & 1.28 to 1.92 \\
\hline \multicolumn{3}{|l|}{ Household level } \\
\hline \multicolumn{3}{|l|}{ Income } \\
\hline High & 1.00 & \\
\hline Middle & 1.55 & 1.11 to 2.18 \\
\hline Low & 1.09 & 0.75 to 1.57 \\
\hline \multicolumn{3}{|l|}{ Health insurance type } \\
\hline Health insurance & 1.00 & \\
\hline Medical Aid & 0.61 & 0.46 to 0.81 \\
\hline \multicolumn{3}{|c|}{ Number of people with a disability } \\
\hline 0 & 1.00 & \\
\hline$\geq 1$ & 1.26 & 1.05 to 1.51 \\
\hline \multicolumn{3}{|c|}{ Number of people over 65 years } \\
\hline 0 & 1.00 & \\
\hline 1 & 1.43 & 1.01 to 2.00 \\
\hline$\geq 2$ & 3.69 & 2.57 to 5.28 \\
\hline \multicolumn{3}{|c|}{ Number of household members } \\
\hline 1 & 1.00 & \\
\hline 2 & 1.42 & 1.01 to 1.99 \\
\hline$\geq 3$ & 1.27 & 0.86 to 1.87 \\
\hline
\end{tabular}

diseases or depression were more likely to experience CHE. Households headed by a woman have increased from $18.5 \%$ (2000) to $25.9 \%$ (2010), and this reflects problems as well as structural changes in South Korea. ${ }^{27}$
Whereas in the past female householders generally resulted from the loss of a spouse, single households have recently increased because of changes in family values. ${ }^{28}$ Labour market discrimination against women limits their economic activities, and career discontinuity occurs because of a patriarchal society that makes them wholly responsible for housework. Income reduction or insecure status of the labour market may result in CHE if a woman loses her husband. ${ }^{29}$ Health-related factors affecting CHE in our study included self-rated health, chronic diseases and depression, similar to the results of previous studies. ${ }^{2} 30-32$

Regarding household level, households that joined the national health insurance system were more likely to experience CHE. The healthcare system in Korea has two elements, national health insurance and Medical Aid. The national health insurance system, which is comprehensively managed in the form of social insurance, is financed by contributions from beneficiaries and provides benefits to them. The other element, Medical Aid, was started in 1977 as a form of public assistance to guarantee the minimum standard of living to low-income families by providing almost free medical services, and is financed by general revenue. ${ }^{33}$ Our results indicated that people supported by Korea's Medical Aid programme had significantly lower CHE, which is probably due to the fact that Medical Aid beneficiaries have very low OOP payments. At least for low-income households, it appears that Medical Aid contributes more financial protection than alternative insurance programmes. ${ }^{34}$ In contrast, households with elderly people and those containing individuals with a disability had significantly higher odds of experiencing CHE, similar to previous studies. ${ }^{35} 36$

This study has a few limitations. First, comprehensive medical expenses, including expenses for health functional food and check ups etc, were used, even though the WHO defined CHE as inevitable and involuntary spending; therefore, CHE may be overestimated. However, according to statistics from the 2012 Korean Health Panel (KHP), similar to KOWEPS, necessary medical costs including inpatient, outpatient and emergency treatment and drugs account for $88.8 \%$ of comprehensive medical expenses. This rate indicates that the effect of CHE by voluntary spending may be modest. Second, because diverse criteria (10-40\%) were used as the threshold of CHE, comparing our results with those of previous research is difficult. Thus, this study referred to previous studies which used a $40 \%$ threshold as recommended by the WHO. In addition, the CHE index does not take account of households that did not receive medical treatment because of their inability to pay and indirect costs such as loss in wages. Third, because a few conditions may not have been diagnosed, the actual prevalence of chronic diseases is probably higher than that reported in the KOWEPS. Fourth, because this research analysed data from a higher proportion of lowincome people, these study findings cannot be easily generalised. 
Table 3 Changes in economic status associated with catastrophic health expenditure in households according to income level

\begin{tabular}{|c|c|c|c|c|c|c|}
\hline \multirow[b]{2}{*}{ Variable } & \multicolumn{2}{|c|}{$\begin{array}{l}\text { Low-income } \\
\text { population }\end{array}$} & \multicolumn{2}{|c|}{$\begin{array}{l}\text { Middle-income } \\
\text { population }\end{array}$} & \multicolumn{2}{|c|}{$\begin{array}{l}\text { High-income } \\
\text { population }\end{array}$} \\
\hline & $\overline{\text { OR }^{*}}$ & $95 \% \mathrm{Cl}$ & $\overline{\text { OR }^{\star}}$ & $95 \% \mathrm{Cl}$ & $\overline{\text { OR }^{\star}}$ & $95 \% \mathrm{Cl}$ \\
\hline Employed $\rightarrow$ employed & 1.00 & & 1.00 & & 1.00 & \\
\hline Unemployed $\rightarrow$ employed & 1.06 & 0.58 to 1.95 & 0.63 & 0.24 to 1.62 & 1.16 & 0.26 to 5.07 \\
\hline Employed $\rightarrow$ unemployed & 3.52 & 2.44 to 5.10 & 1.49 & 0.75 to 2.97 & 2.10 & 0.60 to 7.37 \\
\hline Unemployed $\rightarrow$ unemployed & 1.67 & 1.29 to 2.16 & 1.53 & 1.03 to 2.28 & 1.29 & 0.58 to 2.87 \\
\hline
\end{tabular}

${ }^{*}$ Adjusted for age, sex, education, marital status, disability, chronic disease, depression, household income, type of health insurance, number of people with a disability/people over 65 years/number of household members.

Despite these limitations, this study is meaningful because it is the first to examine the impact of employment status changes on CHE in low-income people as well as the general population of South Korea. Because the Korean government has continuously increased medical support programmes for low-income people, we believe this research could provide significant evidence for expanding this assistance. Second, the longitudinal design of this research allows us to assess the continuity and stability of a few attributes of a sample group by repeatedly examining the same people. Another important strength of the longitudinal design is that cohort effects can be avoided because this study analysed one group of individuals over time, rather than comparing several groups that include different generations.

\section{CONCLUSIONS}

Households containing people who experienced changes in job status from employed to unemployed or who were unemployed with no status change were more likely to incur CHE than households with people who were continuously employed. In addition, lowincome families with members who had either lost a job or were already unemployed were more likely to incur CHE than low-income households of people continuously holding a job. Given the insecure employment status of low-income people, they are more likely to face barriers in obtaining needed health services. Meeting their healthcare needs is an important consideration.

Contributors JWC conceived the study. THK and SIJ helped to draft the manuscript and provided a variety of comments. SYJ and W-RK performed the statistical analysis. ECP participated in its design and coordination. All authors read and approved the final manuscript.

Funding This work was supported by the Korean Medical Association Grant funded by the Korean Government (2013-94).

Competing interests None declared.

Provenance and peer review Not commissioned; externally peer reviewed.

Data sharing statement Extra data can be accessed via the Dryad data repository at http://datadryad.org/ with the doi:10.5061/dryad.nr6bf.

Open Access This is an Open Access article distributed in accordance with the Creative Commons Attribution Non Commercial (CC BY-NC 4.0) license, which permits others to distribute, remix, adapt, build upon this work noncommercially, and license their derivative works on different terms, provided the original work is properly cited and the use is non-commercial. See: http:// creativecommons.org/licenses/by-nc/4.0/

\section{REFERENCES}

1. OECD. Health at a glance 2014: OECD indicators. Organization for Economic Cooperation and Development, 2014.

2. Choi JW, Choi JW, Kim JH, et al. Association between chronic disease and catastrophic health expenditure in Korea. BMC Health Serv Res 2015;15:26.

3. OECD. Health at a glance 2013: OECD indicators. Organization for Economic Cooperation and Development, 2013.

4. Chuma J, Maina T. Catastrophic health care spending and impoverishment in Kenya. BMC Health Serv Res 2012;12:413.

5. Zare $\mathrm{H}$, Trujillo AJ, Leidman E, et al. Income elasticity of health expenditures in Iran. Health Policy Plan 2013;28:665-79.

6. Wagstaff A. Poverty and health sector inequalities. Bull World Health Organ 2002;80:97-105.

7. Lee TJ, Lee HJ, Kim YH. Analysis of catastrophic health expenditures using 1st wave Korea health panel data. Korean $J$ Health Econ Policy 2012;18:95-111.

8. Son SI, Shin YJ, Kim CY. Factors influencing household catastrophic health expenditure of the poor. Health Soc Welfare Rev 2010;30:92-110.

9. Lee HJ, Lee TJ. Factors associated with incidence and recurrence of household catastrophic health expenditure in South Korea. Korean Soc Secur Stud 2012;28:39-62.

10. Jeong CL, Lee TJ. The factors influencing the occurrence and recurrence of catastrophic health expenditure amonghouseholds in Seoul. Health Policy Manag 2012;22:275-96.

11. Choi JK, Jeong HS, Shin JW, et al. Effects of the benefit extension policy on the burdening of health care expenditure for households with patients of chronic or serious case. Health Policy Manag 2011:21:159-78.

12. Choi JW, Kim TH, Kim JH, et al. Impact of changes in economic status on catastrophic health expenditures among households with people with a disability in South Korea. Edorium J Disabil Rehabil 2015;1:1-8.

13. Kwon SM, Yang BM, Lee TJ, et al. Equity in health care utilization in Korea. Korean J Health Econ Policy 2003;9:13-23.

14. van Doorslaer $E$, Wagstaff $A$, Bleichrodt $H$, et al. Income-related inequalities in health: some international comparisons. J Health Econ 1997;16:93-112.

15. Lu JF, Leung GM, Kwon S, et al. Horizontal equity in health care utilization evidence from three high-income Asian economies. Soc Sci Med 2007;64:199-212.

16. O'Donnell O, van Doorslaer E, Rannan-Eliya RP, et al. Who pays for health care in Asia? J Health Econ 2008;27:460-75.

17. Shin HS, Kim MK, Kim JS. Fairness of health care financing: progressivity and redistributive effect. Health Policy Manag 2004;14:17-33.

18. Moon SW, Han EJ, Hwang YH, et al. Comparison of medical expenditure equity in cancer and non-cancer households. Health Soc Sci 2011;30:131-50.

19. Ilesanmi OS, Adebiyi AO, Fatiregun AA. National health insurance scheme: how protected are households in Oyo State, Nigeria from catastrophic health expenditure? Int $J$ Health Policy Manag 2014;2:175-80.

20. Li Y, Wu Q, Xu L, et al. Factors affecting catastrophic health expenditure and impoverishment from medical expenses in China: policy implications of universal health insurance. Bull World Health Organ 2012;90:664-71. 
21. Xu K, Evans DB, Kawabata K, et al. Household catastrophic health expenditure: a multicountry analysis. Lancet 2003;362:111-17.

22. Song HY, Choi JW, Park EC. The effect of economic participatory change on unmet needs of health care among Korean adults. Health Policy Manag 2015;25:11-21.

23. Storeng KT, Baggaley RF, Ganaba R, et al. Paying the price: the cost and consequences of emergency obstetric care in Burkina Faso. Soc Sci Med 2008;66:545-57.

24. Song EC, Shin YJ. The effect of catastrophic health expenditure on the transition to and persistence of poverty in South Korea: analysis of the Korea Welfare panel study data, 2007-2012. Health Policy Manag 2014;24:242-53.

25. Woo HK, Moon OR, Park JH. The difference of health according to employment status and income level of wage-earners. Health Policy Manag 2009;19:85-110.

26. Shin YJ, Son Jl. The prevalence and association factors of unmet medical need-using the 1st and 2nd Korea welfare panel data. Health Soc Res 2009;29:111-42.

27. Kim EH. Social exclusion risk of female-headed Households. Korean Soc Secur Stud 2014;30:31-58.

28. Hong EY, Kim SD. Health status and affecting factors related to job among Korean women employees. J Korea Acad Industr Coop Soc 2012:13:4107-18.
29. Park JG. The analysis of the causes of female-headed household and poverty characteristics. Womens Stud 2009;77:109-41.

30. Jiang $\mathrm{C}, \mathrm{Ma} \mathrm{J}$, Zhang $\mathrm{X}$, et al. Measuring financial protection for health in families with chronic conditions in Rural China. BMC Public Health 2012;12:988.

31. Kim KS, Lee HO. Household catastrophic health expenditure and unmet needs depending on the types of health care system. Social Welfare Policy 2012;39:255-79.

32. Seo NG, Ahn SJ, Kang TW, et al. The study of estimating household catastrophic health expenditure using Korea health panel data. Korean J Health Econ Policy 2015;21:79-102.

33. Oh JJ. Success of case management for medical aid initiative in Korea. Health Soc Care Community 2013;21:464-71.

34. Choi JW, Park EC, Chun SY, et al. Health care utilization and costs among medical-aid enrollees, the poor not enrolled in medical-aid, and the near poor in South Korea. Int $J$ Equity Health 2015;14:128.

35. Choi JW, Cho KH, Choi Y, et al. Changes in economic status of households associated with catastrophic health expenditures for cancer in South Korea. Asian Pac J Cancer Prev 2014;15:2713-17.

36. Noh SH. The longitudinal study on the factors of catastrophic health expenditure among disabled elderly households. Korean J Soc Welfare 2012;64:51-77. 